\title{
Isoproterenol Increases CREB Phosphorylation and Olfactory Nerve-Evoked Potentials in Normal and 5-HT-Depleted Olfactory Bulbs in Rat Pups Only at Doses That Produce Odor Preference Learning
}

\author{
Qi Yuan, ${ }^{1}$ Carolyn W. Harley, ${ }^{2,3}$ Jamie C. Bruce, ${ }^{2}$ Andrea Darby-King, ${ }^{1}$ \\ and John H. McLean ${ }^{1}$ \\ ${ }^{1}$ Division of Basic Medical Sciences, ${ }^{2}$ Department of Psychology, Memorial University of Newfoundland, St. John's, \\ Newfoundland A1B 3V6, Canada
}

\begin{abstract}
Norepinephrine (NE) and serotonin (5-HT) are important modulators of early odor preference learning. NE can act as an unconditioned stimulus (UCS), whereas 5-HT facilitates noradrenergic actions. In this study, we examined the phosphorylation of an important transcription factor, cAMP response element binding protein (CREB), which has been implicated in long-term-memory formation (McLean et al. 1999) during NE-induced odor preference learning in normal and olfactory bulb 5-HT-depleted rat pups. We also examined NE modulation of olfactory nerve-evoked field potentials (ON-EFPs) in anesthetized normal and bulbar 5 -HT depleted pups. Systemic injection of $2 \mathrm{mg} / \mathrm{kg}$ isoproterenol ( $\beta$-adrenoceptor agonist) induced odor preference learning, enhanced pCREB expression in the olfactory bulbs at $10 \mathrm{~min}$ after odor pairing, and increased ON-EFPs in normal rat pups but not in bulbar 5-HT-depleted rat pups. A dose of $6 \mathrm{mg} / \mathrm{kg}$ isoproterenol, which was ineffective in modulating these measures in normal rat pups, induced odor preference learning, enhanced phosphorylated CREB (pCREB) expression, and increased ON-EFPs in bulbar 5-HT-depleted pups. These outcomes suggest that NE and 5-HT promote specific biochemical and electrophysiological changes that may critically underlie odor preference learning.
\end{abstract}

The neonate rat forms a preference to odors that are paired with either tactile stimulation (stroking) or $2 \mathrm{mg} / \mathrm{kg}$ of the $\beta$-adrenoceptor agonist isoproterenol (Sullivan et al. 1989; Sullivan and Wilson 1991; Langdon et al. 1997). In this early olfactory learning paradigm, stroking has been shown to activate the locus coeruleus (Nakamura et al. 1987), which releases norepinephrine (NE) in the main olfactory bulb and engages $\beta$-adrenoceptors (Sullivan and Wilson 1994; Woo et al. 1996). Intrabulbar infusion of the $\beta$-adrenoceptor antagonist propranolol prevents the development of the conditioned odor preference (Sullivan et al. 1989). Co-activation of the glutamatergic olfactory nerve $(\mathrm{ON})$ input (Berkowicz et al. 1994; Ennis et al. 1996) and $\beta$-adrenoceptors is hypothesized to be critical for triggering the long-term change in olfactory bulb processing that mediates conditioned odor preference learning (McLean et al. 1999). The pairing of odor with the $\beta$-adrenoceptor agonist exhibits an inverted U-curve, with both a lower dose $(1 \mathrm{mg} / \mathrm{kg})$ and a higher dose $(4 \mathrm{mg} / \mathrm{kg})$ of isoproterenol being ineffective relative to

${ }^{3}$ Corresponding author.

E-MAIL charley@play.psych.mun.ca; FAX (709) 737-4000.

Article and publication are at www.learnmem.org/cgi/doi/10.1101/ $\operatorname{lm} .35900$. the moderate dose $(2 \mathrm{mg} / \mathrm{kg})$ that is optimal for learning (Sullivan et al. 1989; Langdon et al. 1997). Selective serotonin (5-HT) fiber depletion in the olfactory bulb of rat pups shifts the isoproterenol inverted U-curve so that a higher dose $(6 \mathrm{mg} / \mathrm{kg})$ is required for learning, and the normal optimal moderate dose ( $2 \mathrm{mg} / \mathrm{kg}$ ) is ineffective (Langdon et al. 1997).

Electrophysiological recordings performed in the olfactory bulb of rat pups that have undergone conditioned odor preference training have shown a significant decrease in the ratio of excitation to inhibition in single-unit mitral cell activity recorded in the olfactory bulb (Wilson and Sullivan 1991). However, it was not possible in the unit recording studies to know if the mitral cells encoding the learned odor were selectively sampled. The increased inhibition might reflect increased lateral inhibition concomitant with stronger signaling in the conditioned odor pathway. Disinhibition of mitral cells from granule cell GABAergic effects at dendrodendritic granule cell-mitral cell synapses (Jahr and Nicoll 1982; Trombley and Shepherd 1992; Okutani et al. 1999) has been suggested to play a critical role in conditioned olfactory learning. Such an effect might be expected to potentiate rather than inhibit $\mathrm{ON}$ throughput during ac-

LEARNING \& MEMORY 7:413-421 @ 2000 by Cold Spring Harbor Laboratory Press ISSN1072-0502/00 \$5.00

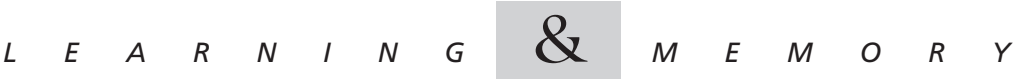

$$
\begin{aligned}
& \text { www.learnmem.org }
\end{aligned}
$$


quisition. The occurrence of disinhibition is supported by evidence that NE applied to the external plexiform layer decreases inhibitory postsynaptic potentials recorded in the granule cell layer by stimulating ONs (Jahr and Nicoll 1982). Paired pulse inhibition of the mitral cells is also suppressed by injections of NE or isoproterenol (Jahr and Nicoll 1982; Wilson and Leon 1988).

In another direction, extensive research has been conducted to identify the molecular components of synaptic plasticity underlying memory formation. Emerging from these studies is the identification of cAMP response element binding protein (CREB) as an important modulator of memory formation (Silva et al. 1998). Its activation is required to initiate the cellular events underlying long-termmemory formation in a variety of species (Yin and Tully 1996; Abel and Kandel 1998; Bartsch et al. 1998; Silva et al. 1998). CREB phosphorylation at ser 133 by different protein kinases (Thompson et al. 1995; Deisseroth et al. 1996; English and Sweatt 1997; Finkbeiner et al. 1997; Impey et al. 1998; Shieh et al. 1998; Xing et al. 1998) has been implicated as the initial step of CREB-related gene transcription (Walton and Dragunow 2000). Down-regulation of phosphorylated CREB (pCREB) or of related protein kinases impairs long-term-memory formation (Abel et al. 1997; Silva et al. 1998). Electrophysiological evidence in hippocampal cultures (Bito et al. 1996; Deisseroth et al. 1998; Mermelstein et al. 2000) suggests that CREB phosphorylation responds to specific synaptic signals engaging both $N$-methylD-aspartate (NMDA) receptors and L-type calcium channels. Increased pCREB activation has been shown to occur in the mitral cells of rat pup olfactory bulbs that are pretreated with effective pairings of odor and stroking (McLean et al. 1999), a procedure in which both NMDA receptors and calcium channels are involved.

In the present study, we asked, first, whether the pairing of odor with a behaviorally effective dose of isoproterenol $(2 \mathrm{mg} / \mathrm{kg}$ ) could produce the same pCREB increase seen previously after odor paired with stroking. Further, we examined whether a higher dose of isoproterenol $(6 \mathrm{mg} / \mathrm{kg}$, a dose that cannot induce preference learning in normal rat pups), when paired with odor, could still increase pCREB. Then, the importance of pCREB in the mediation of serotonergic modulation of NE-induced odor preference in rat pups was examined by using selective serotonergic depletion of the olfactory bulb. If pCREB is specifically involved in learning, a higher dose of isoproterenol $(6 \mathrm{mg} / \mathrm{kg})$ should be required to enhance pCREB expression. This would parallel the previous behavioral model in which selective 5-HT depletion of olfactory bulbs shifted the effective dose of isoproterenol so that a higher dose $(6 \mathrm{mg} / \mathrm{kg})$ was required to induce odor preference learning.

Second, to illuminate possible changes in synaptic transmission in olfactory circuitry, which may trigger the subcellular signal transduction underlying associative learn- ing or functionally support such learning, we asked whether behaviorally optimal doses of isoproterenol altered ON-evoked potentials. Normal rat pups and pups with 5-HT depletion in the olfactory bulbs were again tested.

If pCREB is critical for odor preference learning, and if odor preference learning alters the response to ON input, we would expect that only behaviorally optimal doses of isoproterenol would selectively change both pCREB expression and the ON-evoked potential in rat pups with either normal or 5-HT-depleted olfactory bulbs.

\section{RESULTS AND DISCUSSION}

\section{Experiment 1}

To test the hypothesis that pairing odor with a behaviorally effective dose of the $\beta$-adrenoceptor agonist isoproterenol triggers phosphorylation of CREB, we subcutaneously injected isoproterenol into normal rat pups $40 \mathrm{~min}$ before conditioned pairing with odor (experiment 1a). Isoproterenol can completely substitute for stroking as an unconditioned stimulus during odor conditioning (Sullivan et al. 1989). This effect is consistent with the observed activation of locus coeruleus neurons, the source of NE in neonate rat olfactory bulbs, by somatosensory stimulation (Nakamura et al. 1987). Because a selective pCREB increase was observed in olfactory conditioned preference learning (increased pCREB in the bulbs of odor-conditioned pups but not in the bulbs of the pups that were trained by odor or stroke alone) (McLean et al. 1999), we hypothesized that the intracellular cAMP second messenger system, activated by NE input to the $\beta$-adrenoceptor, works synergistically with the $\mathrm{Ca}^{2+}$ entry triggered by glutamatergic olfactory input to influence CREB phosphorylation and the downstream gene transcription, which are necessary for long-term-memory formation. In the present study, direct activation of the $\beta$-adrenoceptor by isoproterenol should have the same effect as the tactile stimulation in odor preference learning. In addition, given the observation that 5-HT normally promotes the efficacy of the $\beta$-adrenoceptor agonist isoproterenol as an unconditioned stimulus during olfactory learning, we predicted that a higher dose of isoproterenol would be required in 5-HTdepleted animals to induce an increase in pCREB comparable to that observed in normal animals (experiment $1 \mathrm{~b}$ ).

Figure 1 shows the change of pCREB in the olfactory bulbs produced by pairing two doses of the $\beta$-adrenoceptor agonist isoproterenol with odor, and the odor preference results in normal rat pups. Behavioral results showed that $2 \mathrm{mg} / \mathrm{kg}$ isoproterenol induced significant odor preference learning among rat pups that received that dose compared with either those in the saline group $(P<0.01)$ or in the $6 \mathrm{mg} / \mathrm{kg}$ isoproterenol group $(P<0.05)$ (Fig. 1A). Correspondingly, the olfactory bulbs of pups that were trained by pairing odor with $2 \mathrm{mg} / \mathrm{kg}$ isoproterenol injection showed increased pCREB expression $10 \mathrm{~min}$ after training com-

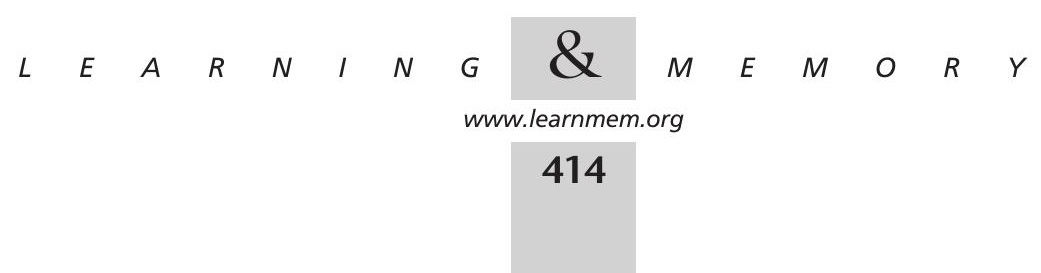



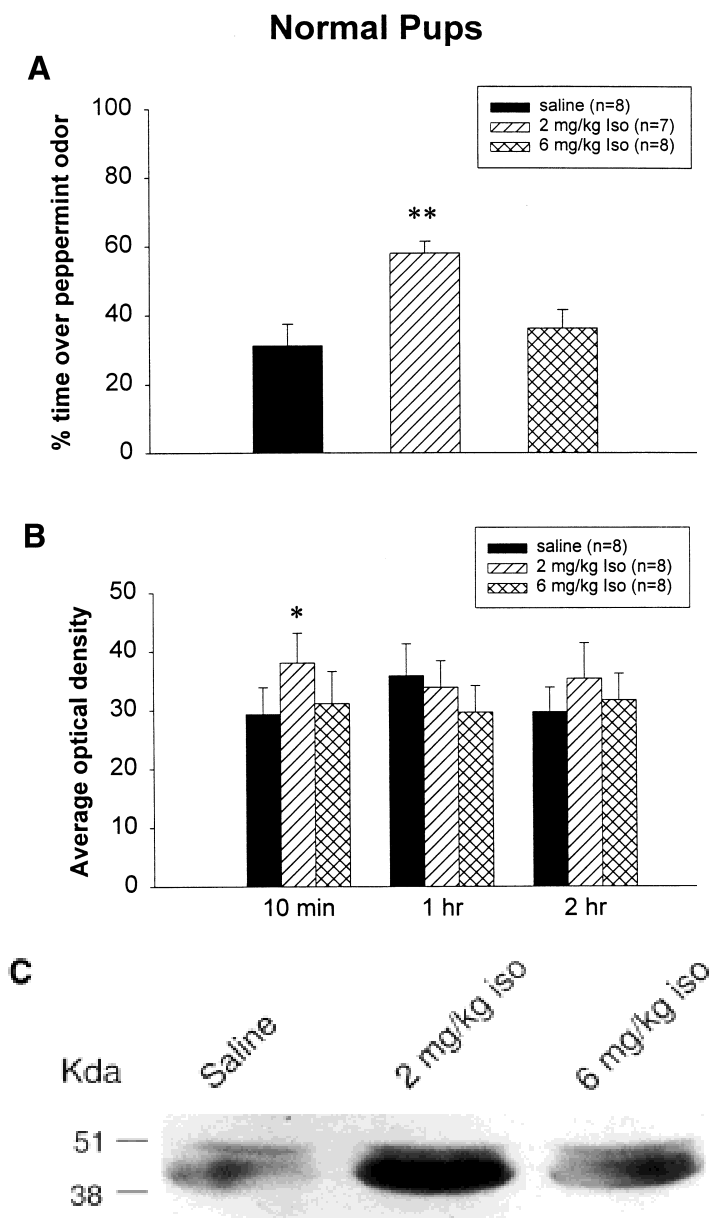

Figure 1 (A) Odor preference test in normal pups from the saline, $2 \mathrm{mg} / \mathrm{kg}$ isoproterenol, and $6 \mathrm{mg} / \mathrm{kg}$ isoproterenol groups after odor-only training. ${ }^{* *} P<0.01$. $(B)$ Western results showing the average optical density (mean \pm SEM) of pCREB in the olfactory bulbs of normal rat pups. ${ }^{*} P<0.05$. (C) Representative Western blot showing pCREB levels in the normal olfactory bulbs from different treatment groups at $10 \mathrm{~min}$ after odor exposure. pCREB bands locate at $43 \mathrm{kD}$. (iso) Isoproterenol.

pared with pups from other treatment groups (Fig. 1B,C). Statistical analysis revealed a significant treatment effect $\left(\mathrm{F}_{2,21}=3.87 ; P=0.046\right)$. In the post hoc Tukey-Kramer tests, the $2 \mathrm{mg} / \mathrm{kg}$ isoproterenol group (AVG = 38.0) showed significantly higher pCREB $(P<0.05)$ than did the saline group $(A V G=29.3)$, whereas there was no significant difference between the groups given saline and $6 \mathrm{mg}$ / $\mathrm{kg}$ isoproterenol (AVG = 31.2). Analysis of Western blots from longer time durations ( 1 and $2 \mathrm{~h}$ ) after conditioning did not show any significant difference among the various treatment groups (Fig. 1B).

Odor preference tests showed that only the $6 \mathrm{mg} / \mathrm{kg}$ isoproterenol group exhibited a significant increase in odor preference when compared with either the saline or the 2 $\mathrm{mg} / \mathrm{kg}$ isoproterenol groups $(P<0.01$; Fig. $2 \mathrm{~A})$ in bulbar 5-HT-depleted pups. The same pCREB measurements on

\section{5-HT Depleted Pups}

A

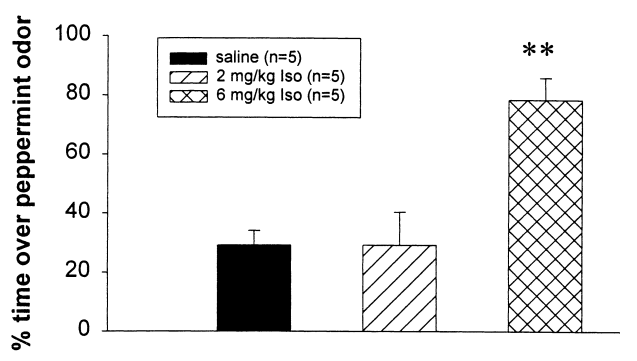

B

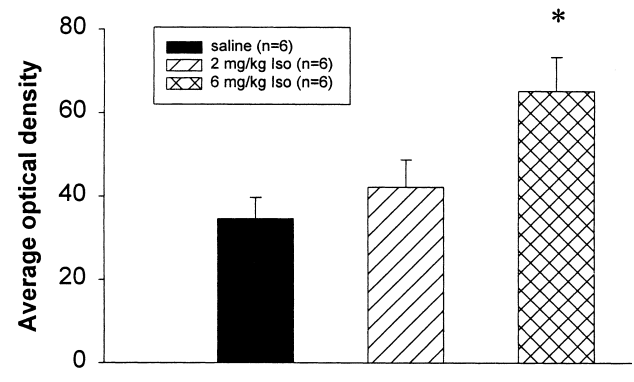

C

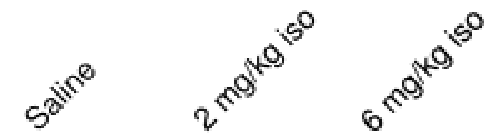

Kda

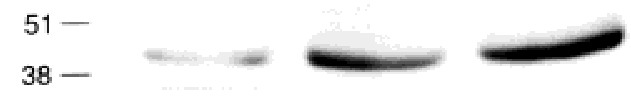

Figure $2(A)$ Odor preference test in bulbar 5-HT-depleted pups after odor-only training. ${ }^{* *} P<0.01$. (B) Western results showing the average optical density (mean \pm SEM) of pCREB in the olfactory bulbs of 5-HT-depleted rat pups. $* P<0.05$. (C) Representative Western blot showing pCREB levels in the 5-HT-depleted olfactory bulbs from different treatment groups at $10 \mathrm{~min}$ after odor exposure. (iso) Isoproterenol.

bulbar 5-HT-depleted animals were examined only at the 10-min interval after training for Western blots because we had not shown any difference of pCREB expression at longer time intervals in experiment 1a. In the present experiment, we found that the $6 \mathrm{mg} / \mathrm{kg}$ isoproterenol group but not the $2 \mathrm{mg} / \mathrm{kg}$ isoproterenol group showed significantly increased pCREB (Fig. 2B,C). Following a one-way ANOVA analysis $\left(\mathrm{F}_{2,15}=5.61 ; P=0.015\right)$, Tukey-Kramer tests revealed a significant difference $(P<0.05)$ between the $6 \mathrm{mg} / \mathrm{kg}$ isoproterenol group $(\mathrm{AVG}=65.1)$ and the saline group $(A V G=34.6)$. No significant difference was found between the saline and the $2 \mathrm{mg} / \mathrm{kg}$ isoproterenol groups $(\mathrm{AVG}=42.3$; Fig. $2 \mathrm{~B})$.

Enhanced pCREB expression has been shown in neonate rat olfactory bulbs after pairing of odor with stroking (McLean et al. 1999), a procedure demonstrated to induce reliable preference learning (Sullivan et al. 1989, 1991;

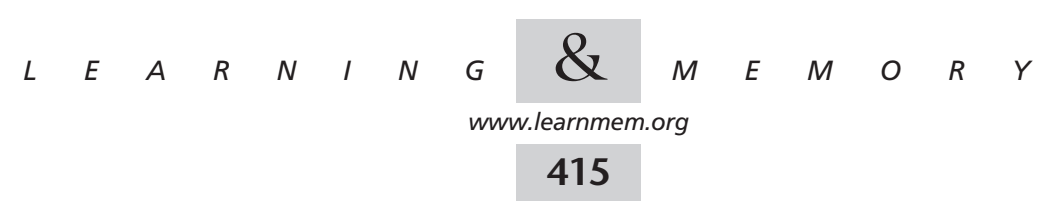


McLean et al. 1992). It is hypothesized that the observed increase in PCREB induced by stroking was the result of tactile stimulation enhancing NE release from the locus coeruleus and activating $\beta$-adrenoceptors in the olfactory bulb concomitant with glutamatergic receptor activation by odor input. Here, we demonstrate that exogenous injection of 2 $\mathrm{mg} / \mathrm{kg}$ isoproterenol, a dose that completely substitutes for stroking in odor preference learning, when paired with peppermint odor, increased pCREB expression in the olfactory bulbs of normal pups.

In contrast, a higher dose of isoproterenol (6 mg/kg) was required to increase pCREB as well as to induce odor preference in bulbar 5-HT-depleted animals. These results correlate with our previous work suggesting that 5-HT acting through $5-\mathrm{HT}_{2}$ receptors normally promotes noradrenergic-induced plasticity in the olfactory bulb (McLean et al. 1999). In the mammalian model, 5-HT receptor activation does not by itself increase cAMP (Morin et al. 1992), but $5-\mathrm{HT}_{2}$ activation potentiates isoproterenol or adenylate cyclase-induced cytoplasmic cAMP levels through the phosphatidyl inositol system (Rovescalli et al. 1996). The localized increase of pCREB in mitral cells in the previous study (McLean et al. 1999) suggests that the 5-HT and NE interaction might occur in mitral cells.

Although a late phase of pCREB was observed in another hippocampal LTP plasticity paradigm (Schulz et al. 1999), we failed to show a significant second peak of pCREB at $2 \mathrm{~h}$. It is possible that the high level of stimulation used in the previous hippocampal LTP paradigm may have led to seizure activity, thus recruiting the second peak of pCREB activation. Double peaks have not yet been reported in a natural learning paradigm.

It is clear from our previous study that a conditioningeffective pairing, odor plus stroking (McLean et al. 1999), or in the present experiment, odor plus $2 \mathrm{mg} / \mathrm{kg}$ isoproterenol, but not odor alone or stroking alone, enhances pCREB expression. These findings suggest that both a glutamateinitiated calcium signal (Bozza and Kauer 1998) triggered by odor input and a cAMP/PKA signal initiated by $\beta$-adrenoceptor activation are required to significantly elevate pCREB. The striking result in the present experiment, however, is that odor plus $6 \mathrm{mg} / \mathrm{kg}$ isoproterenol is ineffective in producing either odor preference learning or enhanced pCREB expression. This outcome argues that a critical window for calcium and PKA co-activation of phosphorylation events has been exceeded by pairing odor and the dose of $6 \mathrm{mg} / \mathrm{kg}$ isoproterenol in the normal rat pup. For example, $\mathrm{Ca}^{2+} / \mathrm{CaM}$ activation of the phosphatase cascade (Blitzer et al. 1995; Bito et al. 1996; Winder et al. 1998) may have overridden the cAMP/PKA-mediated inhibition of the same cascade (Blitzer et al. 1995; Winder et al. 1998). The argument that $6 \mathrm{mg} / \mathrm{kg}$ isoproterenol might be producing pharmacological effects that directly interfere with odor learning is countered by the effectiveness of this dose in bulbar
5-HT-depleted pups. The notion of critical windows for intracellular plasticity cascades is not novel. Long-term depression and long-term potentiation occur variously as a function of specific levels of intracellular calcium (Foehring and Lorenzon 1999; Yang et al. 1999). Competition at the level of CREB factors leading to a failure of plasticity has been described (Ptashne 1988), but it has not been suggested previously that a narrow band window exists for the events triggering CREB phosphorylation itself. The present data demonstrate a strong correlation between effective conditioned stimulus plus unconditioned stimulus pairing and pCREB. Experiments are under way to probe a causal role for pCREB in this learning model.

\section{Experiment 2}

We have established that a $\beta$-adrenoceptor agonist, isoproterenol, can completely substitute for tactile stimulation as the unconditioned stimulus in olfactory preference learning, whereas bulbar 5-HT appears to facilitate this noradrenergic action (Langdon et al. 1997). In experiment 1, we hypothesized, and further showed, that the interaction of NE and 5-HT to produce odor preference learning might act through the CAMP second messenger system to induce CREB phosphorylation, which in turn would trigger transcriptional activation of downstream proteins. Here, we examined the electrophysiological changes induced by these modulating neurotransmitter interactions in the olfactory bulb. We hypothesize that the electrophysiological changes we observed reflect critical changes underlying odor preference learning.

A characteristic waveform of a field potential in the external plexiform layer of a normal olfactory bulb stimulated by $\mathrm{ON}$ stimulation is shown in Figure 3. The field potentials recorded $200-300 \mu \mathrm{m}$ below the surface were long lasting (>50 msec) and displayed $\mathrm{N}_{1}$ (kainate/ $\alpha$-amino-

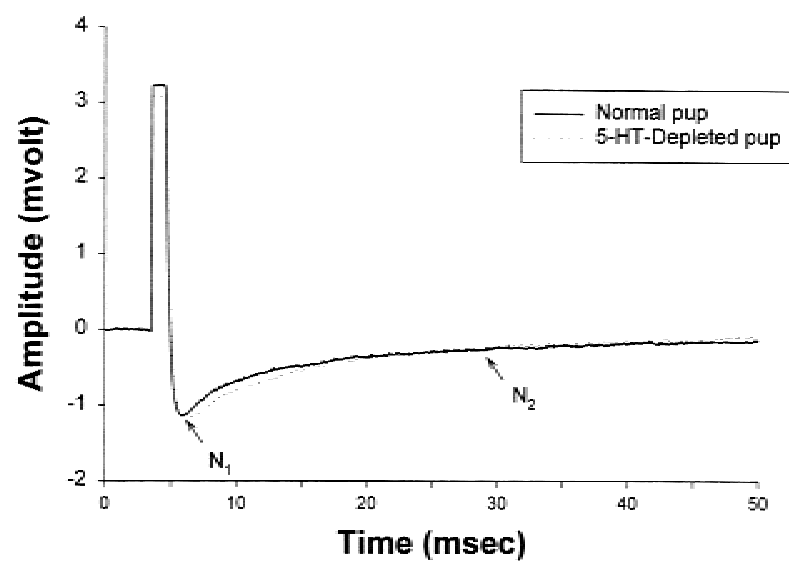

Figure 3 Characteristic waveforms of field potentials in the external plexiform layer of normal and 5-HT-depleted olfactory bulbs by ON stimulation. $N_{1}$ and $N_{2}$ showing the kainate/AMPA receptormediated and NMDA receptor-mediated components described by Aroniadou-Anderjaska et al. (1997).

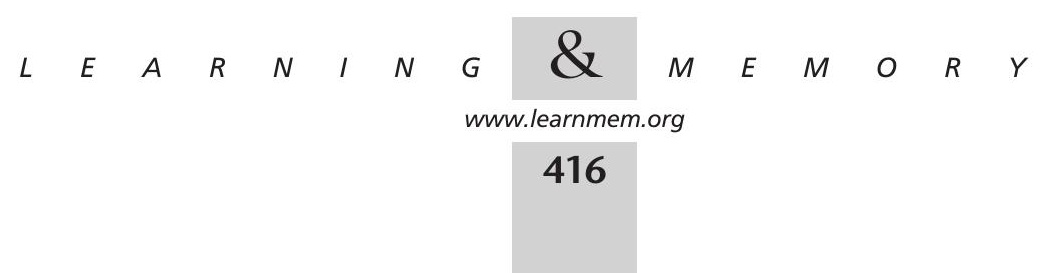


3-hydroxy-5-methyl-4-isoxazolepropionate [AMPA] receptor-mediated) and $\mathrm{N}_{2}$ (NMDA receptor-mediated) components comparable to those described in vitro by AroniadouAnderjaska et al. (1997). Bulbar 5-HT depletion did not appear to alter the ON-evoked potential (Fig. 3).

In experiment $2 \mathrm{a}, 2 \mathrm{mg} / \mathrm{kg}$ isoproterenol produced long-lasting increases in ON-evoked field potential (EFP) area that were evident beginning $30 \mathrm{~min}$ after injection and were most prominent at $60 \mathrm{~min}$ (Fig. 4A,B). ON-EFPs showed little change after injections of saline, $6 \mathrm{mg} / \mathrm{kg}$ isoproterenol, or $20 \mathrm{mg} / \mathrm{kg}$ propranolol. At $60 \mathrm{~min}$, the $2 \mathrm{mg}$ /

\section{Normal Pups}

A

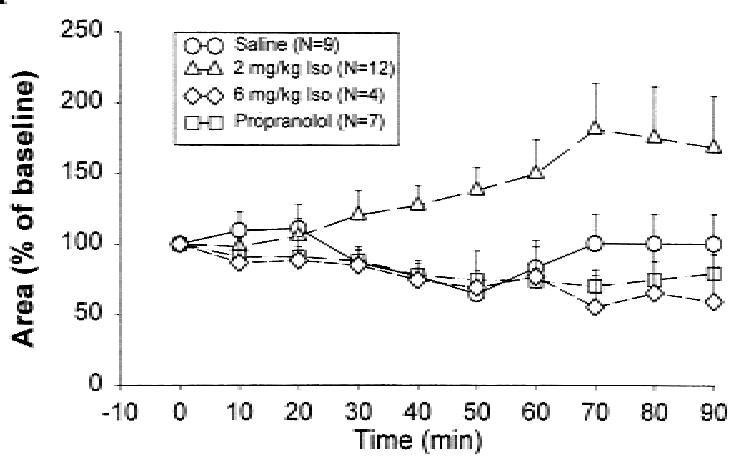

B

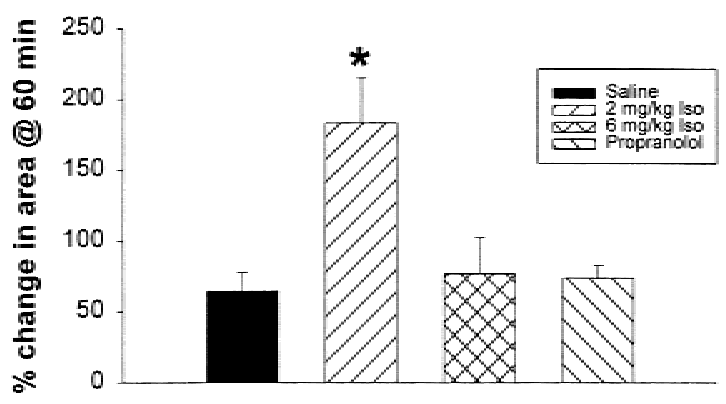

C

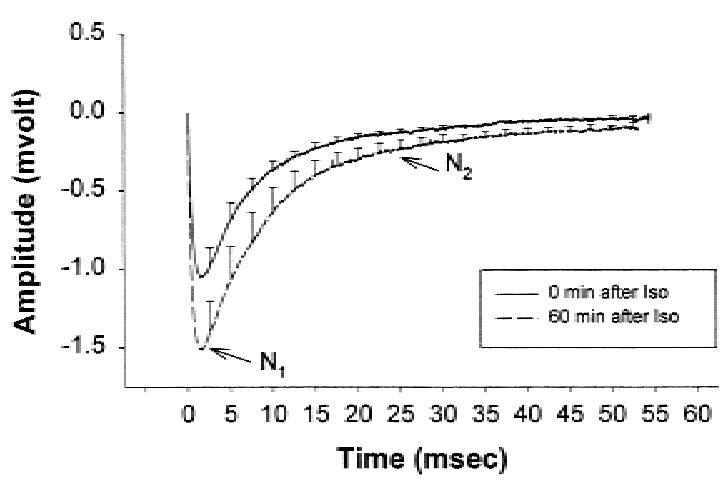

Figure 4 (A) Percentage change of EFP areas from baseline (0 min) among different treatment groups of normal pups at various time intervals (mean \pm SEM). (B) Percentage change of EFP area at 60 min in normal pups. ${ }^{*} P<0.05$. (C) Average effect of $2 \mathrm{mg} / \mathrm{kg}$ isoproterenol on ON-EFPs at 0 and $60 \mathrm{~min}$. (iso) Isoproterenol. $\mathrm{kg}$ isoproterenol group showed a significantly increased percentage of EFP area from $0 \mathrm{~min}\left(\mathrm{~F}_{3,28}=5.897 ; P=0.003\right)$ compared with the saline group $(P<0.01)$, the $6 \mathrm{mg} / \mathrm{kg}$ group $(P<0.05)$, or the propranolol group $(P<0.05)$. The average effect of $2 \mathrm{mg} / \mathrm{kg}$ isoproterenol on ON-EFPs at 0 and $60 \mathrm{~min}$ is illustrated in Figure 4C. Waveform changes suggest that both $\mathrm{N}_{1}$ and $\mathrm{N}_{2}$ components (Aroniadou-Anderjaska et al. 1997) contributed to the increase of EFP area. An attempt was made to estimate the degree of potentiation in both the $\mathrm{N}_{1}$ and $\mathrm{N}_{2}$ components. The peak for $\mathrm{N}_{1}$ occurred $\sim 2.5 \mathrm{msec}$ after the beginning of stimulus artifact in the present in vivo experiments with a 0.5 - to $1-\mathrm{mm}$ stimulatingto-recording electrode separation. This latency is similar to the 4- to 5-msec latency shown by Nicoll (1972) in vivo, in rabbit, using a 1- to 2-mm stimulating-to-recording separation with $\mathrm{ON}$ conduction velocity estimated at $0.34 \mathrm{~m} / \mathrm{sec}$. It contrasts with the peak latency of $10.4 \pm 1.4 \mathrm{msec}$ reported at $33^{\circ} \mathrm{C}$ in vitro by Aroniadou-Anderjaska et al. (1997). The $\mathrm{N}_{1}$ component was measured at the peak. For the $\mathrm{N}_{2}$ component, a 1-msec window was taken from 24 to $25 \mathrm{msec}$ after the stimulus artifact. This component was taken at a point in the waveform shape similar to that used by Aroniadou-Anderjaska et al. (1997) for $\mathrm{N}_{2}$, thus eliminating the contamination of $\mathrm{N}_{2}$ by $\mathrm{N}_{1}$ (Fig. 3). The mean differences at $60 \mathrm{~min}$ after injection of $2 \mathrm{mg} / \mathrm{kg}$ isoproterenol averaged $145 \%$ of the peak at 0 min for $N_{1}$ and $185 \%$ of the mean for $\mathrm{N}_{2}$.

In experiment $2 \mathrm{~b}, 2 \mathrm{mg} / \mathrm{kg}$ isoproterenol was ineffective in 5-HT-depleted bulbs, as was saline, in producing increases in the ON-EFP area (Fig. 5A). In contrast, $6 \mathrm{mg} / \mathrm{kg}$ isoproterenol produced a significant increase in EFP area at $60 \min \left(\mathrm{F}_{2,30}=4.317 ; P=0.025\right)$ when compared with the saline group $(P<0.05$; Fig. $5 \mathrm{~B})$.

Isoproterenol at a dose $(2 \mathrm{mg} / \mathrm{kg})$ that normally produces an effective conditioned odor preference in the 5- to 10-d-old rat pup, and that also increases pCREB expression in olfactory bulbs after conditioned odor preference training (as shown in experiment 1), potentiates the ON-EFP in urethane-anesthetized pups of the same age. This effect was specific for the dose of $2 \mathrm{mg} / \mathrm{kg}$ isoproterenol. The dose of $6 \mathrm{mg} / \mathrm{kg}$ isoproterenol, which does not produce effective odor preference learning in the rat pup (Fig. 1A), did not potentiate the ON-EFP. However, in the olfactory bulbs of rat pups depleted of 5-HT, $6 \mathrm{mg} / \mathrm{kg}$ isoproterenol, but not 2 $\mathrm{mg} / \mathrm{kg}$ isoproterenol, was required to potentiate the $\mathrm{ON}$ EFP. This change in the effective potentiating dose of isoproterenol with 5-HT depletion parallels the result produced by bulbar 5-HT depletion on the acquisition of early conditioned odor preference learning and the activation of pCREB in the olfactory bulbs (Fig. 2A,B). These results also suggest that during early conditioned odor preference acquisition, the glutamatergic ON input is potentiated.

Potentiation of the $\mathrm{N}_{1}$ component of the ON glutamatergic input by its pairing with an effective $\beta$-adrenergic

$$
\begin{array}{ccccccccccccc}
L & E & A & R & N & I & N & G & \mathcal{Q} \\
& \text { www.learnmem.org } \\
& 417 & M & E & M & O & R & Y
\end{array}
$$




\section{5-HT Depleted Pups}

A

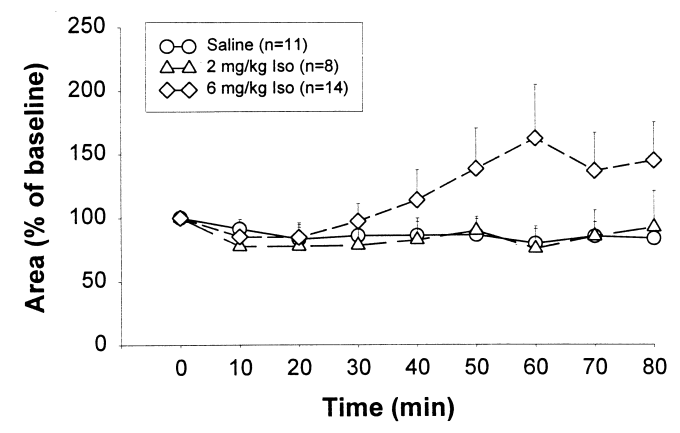

B

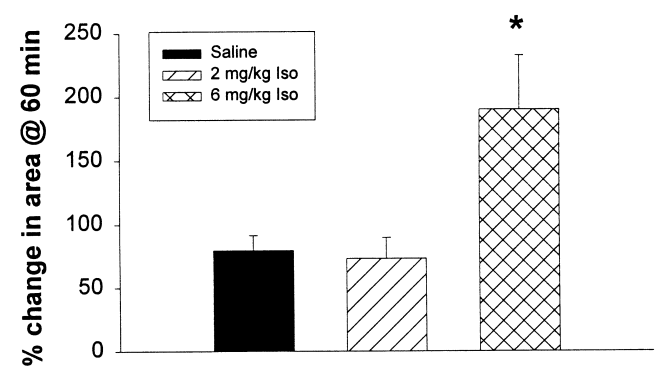

Figure 5 (A) Percentage change of EFP areas from baseline (0 min) of bulbar 5-HT-depleted pups at various time intervals (mean \pm SEM). (B) Percentage change of EFP areas at $60 \mathrm{~min}$ in bulbar 5 -HT-depleted pups. ${ }^{*} P<0.05$. (iso) Isoproterenol.

activation in the anesthetized rat pup can be related to several known effects of $\beta$-adrenergic activation, for example, enhancement of ON depolarization (Kawai et al. 1999), enhancement of postsynaptic glutamate responses (Segal 1982), possibly through increases in membrane resistance, or increased synaptic glutamate through decreased reuptake (Hansson and Ronnback 1991). Potentiation of the $\mathrm{N}_{2}$ component of ON synaptic input may be related to those factors and also to enhanced phosphorylation of NMDA channels related to cAMP elevation and to disinhibition of the mitral cells as the result of $\beta$-adrenergic suppression of granule cell feedback (Wilson and Leon 1988).

An important result of experiment 2 was the failure of the $6 \mathrm{mg} / \mathrm{kg}$ dose of isoproterenol to increase the ON-EFP in normal rat pups. This outcome suggests that the electrophysiological potentiation of $\mathrm{ON}$ input is in some way dose dependent. Dose dependency has not been described for the direct actions of $\beta$-adrenoceptor activation. However, a change in the balance of inhibition and disinhibition in olfactory bulb circuitry may explain the failure to induce a potentiated ON-EFP response using a higher dose $(6 \mathrm{mg}$ / $\mathrm{kg}$ ) of isoproterenol in normal olfactory bulbs. A study of GABAergic control of olfactory learning in 14-d-old rat pups
(Okutani et al. 1999) showed that a low dose of the GABAa receptor antagonist bicuculline infused into olfactory bulbs during odor presentation induces odor preference learning, whereas a high dose induces an aversion. Most important for understanding the present results was their finding that an intermediate dose is ineffective, which supports the hypothesis that a particular level of disinhibition is required for odor preference learning. Although 6-d-old pups do not show aversion learning, the data on 14-d-old pups argue that differences in the balance of inhibition versus disinhibition can prevent learning, as seen in the present study.

The effectiveness of $6 \mathrm{mg} / \mathrm{kg}$ isoproterenol in increasing the ON-EFP in bulbar 5-HT-depleted rat pups suggests that phosphorylation cascades are critical for the electrophysiological effects. If potentiated responses depend on phosphorylation of ion channels, then the failure to recruit intracellular phosphorylation would impair the production of electrophysiological potentiation as well as lead to the failure in CREB phosphorylation.

The present data suggest that the ON input mediating a specific odor is strengthened by preference training during acquisition and likely is more enduring (Hebb 1949). Combined with the pCREB increase in experiment 1 and evidence that pairing of stroking with peppermint odor selectively induces pCREB increases, the electrophysiological data support the hypothesis that enhancement of the odor representation is part of odor preference learning.

\section{General Discussion}

We have investigated the 5-HT and NE interactions underlying olfactory preference learning from behavior to synaptic transmission to postsynaptic biological signal transduction. We are one of the few research groups to look at changes in pCREB during natural learning in a mammalian model. In the present study, we have also tried to illuminate the nature of the electrophysiological changes in the olfactory circuitry that accompany acquisition of odor preference in the neonate rat by pairing an electrical odor input (stimulation of $\mathrm{ON}$ ) with behaviorally effective doses of isoproterenol. This procedure mimics the biological components underlying natural learning. We found a remarkably robust correlation in which a behaviorally effective dose ( 2 $\mathrm{mg} / \mathrm{kg}$ ), but not a higher, ineffective dose (6 mg/kg), of isoproterenol potentiated the EFPs induced by glutamatergic ON input and selectively enhanced CREB phosphorylation in neonate rat olfactory bulbs. A bulbar depletion of 5-HT shifted the dose-dependent effect of NE so that a higher dose $(6 \mathrm{mg} / \mathrm{kg})$ of isoproterenol was required to overcome 5-HT deficiency in the olfactory bulbs for both the electrophysiological change and the increased CREB phosphorylation triggered by behaviorally effective pairing.

There are at least two ways in which the inverted Ucurve for isoproterenol might be understood: (1) The factors that determine the failure to produce electrophysi-

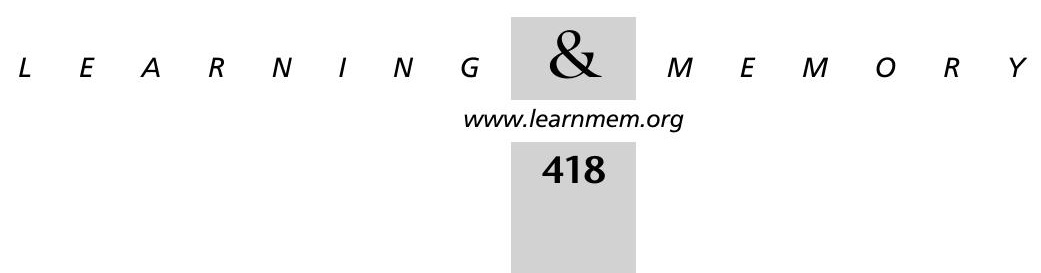


ological potentiation to $\mathrm{ON}$ input are the critical factors in understanding the inverted U-curve for CREB phosphorylation. The failure to phosphorylate CREB is a simple consequence of the failure of potentiation. (2) There are two parallel actions of ineffective pairings of odor input and $\beta$-adrenoceptor activation-one that influences the electrophysiology of the bulb and one that influences the ability of intracellular cascades to promote CREB phosphorylation. The parallel mechanism hypothesis is less parsimonious and seems less likely.

In attempting to understand the failure of electrophysiological potentiation to occur, we have entertained two hypotheses. The failure to produce odor preference learning may relate to an imbalance in mitral cell inhibition/ disinhibition accompanying ineffective doses of isoproterenol. Alternately, because the known effects of isoproterenol are mediated via G-protein activation and recruitment of adenylate cyclase, another possible node for the failure to produce electrophysiological potentiation would be a failure to enhance cAMP levels. It is likely that phosphorylation-sensitive ion channels are involved in the early membrane effects of isoproterenol. Evaluating the dose dependency of cAMP increases in this system would test this hypothesis.

The site of interaction between $\beta$-adrenergic and serotonergic input remains to be identified at the cellular level. However, we suspect the interaction occurs in mitral cells because localized pCREB increases were observed in mitral cells in the olfactory bulbs after conditioning (McLean et al. 1999). The results of the present study seem to suggest that electrophysiological potentiation of olfactory input to the mitral cells necessarily accompanies the acquisition of odor preferences in the rat pup.

\section{MATERIALS AND METHODS}

\section{Experiment 1}

In experiment 1a, 95 Sprague-Dawley rats of both sexes from eight litters were used; in experiment $1 \mathrm{~b}, 33$ rat pups from six litters were used. Three groups were included in each experiment: a saline group, a $2 \mathrm{mg} / \mathrm{kg}$ isoproterenol group, and a $6 \mathrm{mg} / \mathrm{kg}$ isoproterenol group. Litters were culled to 12 pups/litter on PND1 (the day of birth is PND0). In each litter, no more than one pup was assigned to each posttraining survival time group. One littermate from each drug group was used for odor preference testing the day after odor conditioning. The dams were maintained under a 12-h light-dark cycle, with ad libitum access to food and water. All experimental procedures were approved by the Memorial University Institutional Animal Care Committee.

\section{Odor Conditioning and Drug Injection}

The procedure for conditioning has been described by Langdon et al. (1997). Briefly, on PND6, saline or isoproterenol (2 mg/kg or 6 $\mathrm{mg} / \mathrm{kg}$ ) (Research Biochemicals) was injected subcutaneously into normal pups (experiment 1a) or bulbar 5-HT-depleted pups (experiment 1b) $40 \mathrm{~min}$ before their exposure to odor training. The treated pups were removed from the dam 30 min after injection and put on fresh wood bedding. Ten minutes later, pups were placed on peppermint-scented bedding $(0.3 \mathrm{~mL}$ of peppermint $/ 500$ $\mathrm{mL}$ of bedding) for a period of $10 \mathrm{~min}$. After training, one normal pup from each treatment condition was killed at various intervals (10 min, $1 \mathrm{~h}, 2 \mathrm{~h}$; experiment 1a), whereas 5-HT-depleted pups were killed only at 10 min after odor conditioning (experiment $1 \mathrm{~b}$ ). After each rat pup was killed, both olfactory bulbs were removed quickly from the skull, immediately frozen on dry ice, and subsequently stored at $-70^{\circ} \mathrm{C}$ in microcentrifuge tubes. Other treated littermates were used for odor preference testing the next day (PND7).

\section{Preference Testing}

A stainless steel test box $(30 \times 20 \times 18 \mathrm{~cm})$ with a polypropylene mesh screen inside was placed on two trays, which were separated by a $2-\mathrm{cm}$ neutral zone. One tray contained fresh bedding; the other contained peppermint-scented bedding. Each pup was removed from the dam and placed in the neutral zone of the test box. The amount of time the pup spent on either peppermint bedding or normal bedding was recorded for five 1-min trials. A timer was started when a pup moved its snout and one paw into one side of the test box. The percentage of time the pup spent on peppermint bedding over the 5 -min period was calculated. One-way ANOVAs were used to compare different treatment groups, and post hoc tests were performed using the Tukey-Kramer test.

\section{5-HT Depletion}

The procedure for 5-HT depletion of the olfactory bulb has been described by McLean et al. (1993). Briefly, PND1 pups were removed from the dams, pretreated with $10 \mathrm{mg} / \mathrm{kg}$ desipramine by intraperitoneal injection, and placed on fresh bedding. Forty-five minutes later, after being anesthetized by hypothermia on ice, the pups were placed in a modified stereotaxic instrument, and $150 \mathrm{~nL}$ of 5,7-dihydroxytryptamine (5,7-dHT) in Ringer's solution plus $0.02 \%$ ascorbic acid was injected bilaterally into the anterior olfactory nucleus. The pups were returned to the dams after recovery. Immunocytochemistry was performed on the brains of some of the animals to confirm depletion of 5 -HT. This procedure has been shown to produce $>80 \% 5$-HT fiber depletion in the olfactory bulb and is specific for the serotonergic fibers (McLean et al. 1993).

\section{Protein Determination and Western Blot Analysis}

pCREB protein expression was determined by Western blot using previously published methods (McLean et al. 1999). Briefly, each pair of olfactory bulbs was placed in microcentrifuge tubes and ground in $100 \mu \mathrm{L}$ of lysis buffer containing $0.1 \%$ SDS, $1 \%$ NP-40, 20 mM PMSF, $10 \%$ glycine, and $1.37 \mathrm{mM}$ sodium chloride with $1 \mu \mathrm{L} /$ $\mathrm{mL}$ leupeptin, $2 \mathrm{mM}$ PMSF, $8.9 \mathrm{U} / \mathrm{mL}$ aprotinin, and $1 \mathrm{mM}$ sodium orthovanadate. The homogenate was placed on a rotator for $30 \mathrm{~min}$ and then centrifuged at $13,500 \mathrm{rpm}$ for $15 \mathrm{~min}$ at $4^{\circ} \mathrm{C}$. The clear lysate supernatant was stored in $50-\mu \mathrm{L}$ aliquots at $-70^{\circ} \mathrm{C}$. A bicinchoninic acid protein assay kit was used to determine the protein concentration from each pair of olfactory bulbs.

After protein determination was conducted, $20 \mu \mathrm{L}$ of prepared samples were boiled, cooled on ice, and loaded into each lane of an SDS-polyacrylamide gel for each blot. In each sample, 4 $\mu \mathrm{L}$ of $5 \times$ sample buffer $(0.25$ M Tris-HCL, $10 \%$ SDS, $50 \%$ glycerol, $0.025 \%$ bromophenol blue, with $0.5 \mathrm{M}$ dithiothreitol added prior to use) and sufficient water were added to volumes of lysate that contained equal amounts of protein. Color-coded molecular standard (10 $\mu \mathrm{L}$; Bio-Rad) was loaded into a separate lane for each blot. After sample loading, each gel apparatus was attached to a Bio-Rad

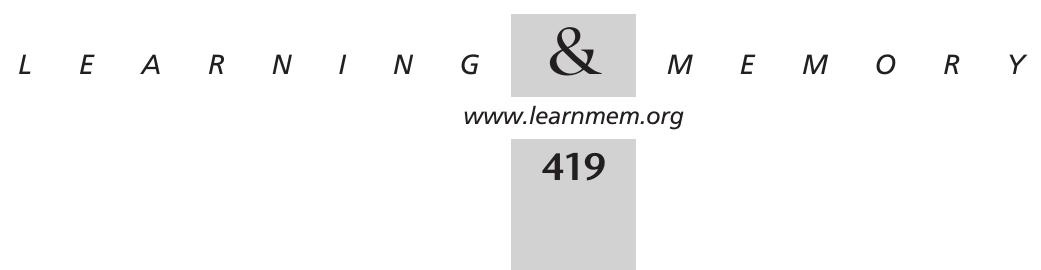


power supply set at $100 \mathrm{mV}$ for $10 \mathrm{~min}$; then the voltage was reset at $150 \mathrm{mV}$ until all the samples were loaded completely. The gelrunning buffer contained $25 \mathrm{mM}$ Tris, $250 \mathrm{mM}$ glycine, $3.5 \mathrm{mM}$ SDS (pH 8.3). Protein transfer to nitrocellulose paper (Hybond ECL, Amersham) was performed at $0.2 \AA$ for $1 \mathrm{~h}$ in transfer solution (25 $\mathrm{mM}$ Tris, $192 \mathrm{mM}$ glycine, 20\% methanol). After transfer, the nitrocellulose blots were processed for detection of pCREB. Briefly, after three 5-min rinses in PBS containing 0.05\% Tween-20 (PBST), the blots were blocked for nonspecific proteins by using 5\% nonfat dry milk in PBST for $1 \mathrm{~h}$. After three 5-min rinses in PBST, the blots were treated with a rabbit polyclonal pCREB antibody $(1: 1500$; Upstate Biotechnology) in PBST overnight at $4^{\circ} \mathrm{C}$. The specificity and sensitivity of this antibody have been shown before (McLean et al. 1999). After three 5-min rinses in PBST and incubation in antirabbit IgG conjugated to horseradish peroxidase for $1 \mathrm{~h}$, the blots were rinsed and visualized by enhanced chemiluminescence (Amersham). Then, the blot papers were immersed in Ponceau S solution to determine if equal amounts of protein were loaded.

Analysis of the Western blots was performed using Chemi Imager software (Alpha Innotech). The average optical density $(A V G=$ integrated density value/area) was recorded in the defined region of the pCREB bands. The background integrated optical density was automatically subtracted from each defined area. Oneway repeated-measure ANOVAs were used to compare different treatment groups at various intervals.

\section{Experiment 2}

A total of 65 Sprague-Dawley rats of both sexes were used in this study. Thirty-three rat pups had their left olfactory bulbs depleted of 5-HT on PND1 or PND2, using the 5-HT depletion method as described for experiment 1 , before electrophysiological recording between PND5 through PND10. In experiment 2a, normal pups were divided into four groups: a saline group, a $2 \mathrm{mg} / \mathrm{kg}$ isoproterenol group, a $6 \mathrm{mg} / \mathrm{kg}$ isoproterenol group, and a $20 \mathrm{mg} / \mathrm{kg}$ propranolol group. In experiment $2 \mathrm{~b}$, three groups as above (the propranolol group was excluded) were included using bulbar 5-HT depleted pups.

\section{Surgery}

On PND5 through PND10, pups were anesthetized with a $2.25 \mathrm{~g} / \mathrm{kg}$ intraperitoneal injection of $20 \%$ urethane. Each pup was placed in a modified stereotaxic apparatus using pressure exerted by the reverse side of normal ear bars to hold the head. The body was supported in a polymer mold through which water warmed to $37^{\circ} \mathrm{C}$ was continually pumped to maintain the body temperature of the pup. The nasal bone overlying the left olfactory bulb was removed using a dental drill.

\section{Electrophysiology}

A bipolar twisted Teflon-coated stainless electrode (MS303, Plastics One) was placed on the rostrolateral surface of the exposed olfactory bulb to stimulate the ON. The stimuli consisted of three square bipolar $40-\mathrm{V}$ pulses of $0.2 \mathrm{msec}$ in duration, $10 \mathrm{sec}$ apart, delivered by a Grass SD9 stimulator. Extracellular field potentials were recorded at varying depths using an unfiltered AC coupled-preamplifier with a saline-filled glass electrode having a tip diameter of $\sim 50$ $\mu \mathrm{m}$. After a depth profile, the recording electrode was usually placed in the external plexiform layer, $\sim 200-300 \mu \mathrm{m}$ deep to the dorsal surface, to maximize the ON-EFP. Either saline, $2 \mathrm{mg} / \mathrm{kg}$ or 6 $\mathrm{mg} / \mathrm{kg}$ isoproterenol, or $20 \mathrm{mg} / \mathrm{kg}$ propranolol in $50 \mu \mathrm{L}$ volume was subcutaneously injected into the pup. Starting from time zero (the time of injection), three recordings with a 10 -sec interval were taken every 10 min for a total time of 80-90 min using a Labmaster A-D board. Asyst software was used to deliver the stimulation and collect and store the EFPs. The EFP area was taken as the area below the baseline (defined by the $5 \mathrm{msec}$ preceding the stimulus) for a 48-msec period after the stimulus artifact. Kruskal-Wallis nonparametric ANOVA tests were performed to compare the EFP areas of each group at every time interval.

\section{ACKNOWLEDGMENTS}

We thank Mark Power and Steve Milway for technical assistance in parts of these experiments. This work was supported by the MRC of Canada (grant 14148).

The publication costs of this article were defrayed in part by payment of page charges. This article must therefore be hereby marked "advertisement" in accordance with 18 USC section 1734 solely to indicate this fact.

\section{REFERENCES}

Abel, T. and Kandel, E. 1998. Positive and negative regulatory mechanisms that mediate long-term memory storage. Brain Res. Rev. 26: 360-378. Abel, T., Nguyen, P.V., Barad, M., Deuel, T.A., Kandel, E.R., and Bourtchouladze, R. 1997. Genetic demonstration of a role for PKA in the late phase of LTP and in hippocampus-based long-term memory. Cell 88: 615-626.

Aroniadou-Anderjaska, V., Ennis, M., and Shipley, M.T. 1997. Glomerular synaptic responses to olfactory nerve input in rat olfactory bulb slices. Neuroscience 79: 425-434.

Bartsch, D., Casadio, A., Karl, K.A., Serodio, P., and Kandel, E.R. 1998. CREB1 encodes a nuclear activator, a repressor, and a cytoplasmic modulator that form a regulatory unit critical for long-term facilitation. Cell 95: 211-223.

Berkowicz, D.A., Trombley, P.Q., and Shepherd, G.M. 1994. Evidence for glutamate as the olfactory receptor cell neurotransmitter. J. Neurophysiol. 71: 2557-2561.

Bito, H., Deisseroth, K., and Tsien, R.W. 1996. CREB phosphorylation and dephosphorylation: A $\mathrm{Ca}^{+}$- and stimulus duration-dependent switch for hippocampal gene expression. Cell 87: 1203-1214.

Blitzer, R.D., Wong, T., Nouranifar, R. Iyengar, R., and Landau, E.M. 1995. Postsynaptic cAMP pathway gates early LTP in hippocampal CA1 region. Neuron 15: 1403-1414.

Bozza, T.C. and Kauer, J.S. 1998. Odorant response properties of convergent olfactory receptor neurons. J. Neurosci. 18: 4560-4569.

Deisseroth, K., Bito, H., and Tsien, R.W. 1996. Signaling from synapse to nucleus: Postsynaptic CREB phosphorylation during multiple forms of hippocampal synaptic plasticity. Neuron 16: 89-101.

Deisseroth, K., Heist, E.K., and Tsien, R.W. 1998. Translocation of calmodulin to the nucleus supports CREB phosphorylation in hippocampal neurons. Nature 392: 198-202.

English, J.D. and Sweatt, J.D. 1997. A requirement for the mitogen-activated protein kinase cascade in hippocampal long term potentiation. J. Biol. Chem. 272: 19103-19106.

Ennis, M., Zimmer, L.A., and Shipley, M.T. 1996. Olfactory nerve stimulation activates rat mitral cells via NMDA and non-NMDA receptors in vitro. NeuroReport 7: 989-992.

Finkbeiner, S., Tavazoie, S.F., Maloratsky, A., Jacobs, K.M. Harris, K.M., and Greenberg, M.E. 1997. CREB: A major mediator of neuronal neurotrophin responses. Neuron 19: 1031-1047.

Foehring, R.C. and Lorenzon, N.M. 1999. Neuromodulation, development and synaptic plasticity. Can. J. Exp. Psychol. 53: 45-61.

Hansson, E. and Ronnback, L. 1991. Receptor regulation of the glutamate, GABA and taurine high-affinity uptake into astrocytes in primary culture. Brain Res. 548: 215-221.

Hebb, D.O. 1949. Title of Chapter 4. The Organization of Bebavior: A Neurophysiological Theory. John Wiley, New York.

Impey, S., Obrietan, K., Wong, S.T., Poser, S., Yano, S., Wayman, G., Deloulme, J.C., Chan, G., and Storm, D.R. 1998. Cross talk between

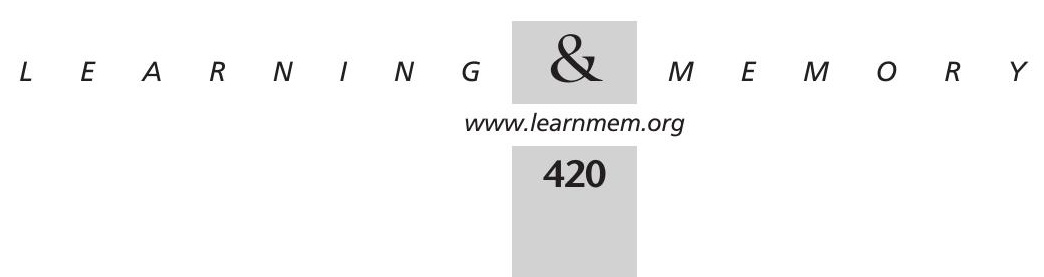


ERK and PKA is required for Ca2 + stimulation of CREB-dependent transcription and ERK nuclear translocation. Neuron 21: 869-883.

Jahr, C.E. and Nicoll, R.A. 1982. Noradrenergic modulation of dendrodendritic inhibition of the olfactory bulb. Nature 297: 227-229.

Kawai, F., Kurahashi, T., and Kaneko, A. 1999. Adrenaline enhances odorant contrast by modulating signal encoding in olfactory receptor cells. Nat. Neurosci. 2: 133-138.

Langdon, P.E., Harley, C.W., and McLean, J.H. 1997. Increased $\beta$ adrenoceptor activation overcomes conditioned olfactory learning deficits induced by serotonin depletion. Dev. Brain Res. 102: 291-293.

McLean, J.H., Darby-King, A., Sullivan, R.M., and King, S.R. 1992. Serotonin and olfactory learning in the neonatal rat. Soc. Neurosci. Abst. Dev. 18: 1201.

1993. Serotonergic influence on olfactory learning in the neonate rat. Behav. Neural Biol. 60: 152-162.

McLean, J.H., Harley, C.W., Darby-King, A., and Yuan, Q. 1999. pCREB in the neonate rat olfactory bulb is selectively and transiently increased by odor preference-conditioned training. Learn. Mem. 6: 608-618.

Mermelstein, P.G., Bito, H., Deisseroth, K., and Tsien, R.W. 2000. Critical dependence of cAMP response element-binding protein phosphorylation on L-type calcium channels supports a selective response to EPSPs in preference to action potentials. J. Neurosci. 20: 266-273.

Morin, D., Sapena, R., Zini, R., and Tillement, J.-P. 1992. Serotonin enhances the $\beta$-adrenergic response in rat brain cortical slices. Eur. $J$. Pharmacol. 225: 273-274.

Nakamura, S., Fumitaka, K., and Sakaguchi, T. 1987. Postnatal development of electrical activity in the locus ceruleus. $J$. Neurophysiol. 58: 510-524

Nicoll, R.A. 1972. Olfactory nerves and their excitatory action in the olfactory bulb. Exp. Brain Res. 14: 185-197.

Okutani, F., Yagi, F., and Kaba, H. 1999. Gabaergic control of olfactory learning in young rats. Neuroscience 93: 1297-1300.

Ptashne, M. 1988. How eukaryotic transcriptional activators work. Nature 335: 683-689

Rovescalli, A.C., Brunello, N., Perez, J., Vitali, S., Steardo, L., and Racagni, G. 1996. Heterologous sensitization of adenylate cyclase activity by serotonin in the rat cerebral cortex. Eur. Neuropsychopharmacol. 3: 463-475.

Schulz, S., Siemer, H., Krug, M., and Höllt, V. 1999. Direct evidence for biphasic cAMP response element-binding protein phosphorylation during long-term potentiation in the rat dentate gyrus in vivo. $J$. Neurosci. 19: 5683-5692

Segal, M. 1982. Norepinephrine modulates reactivity of hippocampal cells to chemical stimulation in vitro. Exp. Neurol. 77: 86-93.

Shieh, P.B., Hu, S.C., Bobb, K., Timmusk, T., and Ghosh, A. 1998. Identification of a signaling pathway involved in calcium regulation of BDNF expression. Neuron 20: 727-740.
Silva, A.J., Kogan, J.H., Frankland, P.W., and Kida, S. 1998. CREB and memory. Annu. Rev. Neurosci. 21: 127-148.

Sullivan, R.M. and Wilson, D.A. 1991. The role of norepinephrine in the expression of learned olfactory neurobehavioral responses in infant rats. Psychobiology 19: 308-312.

. 1994. The locus coeruleus, norepinephrine, and memory in newborns. Brain Res. Bull. 35: 467-472.

Sullivan, R.M., Wilson, D.A., and Leon, M. 1989. Norepinephrine and learning-induced plasticity in infant rat olfactory sytem. J. Neurosci. 9: 3998-4006

Sullivan, R.M., McGaugh, J.L., and Leon, M. 1991. Norepinephrine-induced plasticity and one-trial olfactory learning in neonatal rats. Dev. Brain Res. 60: 219-228.

Thompson, M.A., Ginty, D.D., Bonni, A., and Greenberg, M.E. 1995. L-type voltage-sensitive $\mathrm{Ca} 2+$ channel activation regulates $\mathrm{c}$-fos transcription at multiple levels. J. Biol. Chem. 270: 4224-4235.

Trombley, P.Q. and Shepherd, G.M. 1992. Noradrenergic inhibition of synaptic transmission between mitral and granule cells in mammalian olfactory bulb cultures. J. Neurosci. 12: 3985-3991.

Walton, M.R. and Dragunow, I. 2000. Is CREB a key to neuronal survival? Trends Neurosci. 23: 48-53.

Wilson, D.A. and Leon, M. 1988. Noradrenergic modulation of olfactory bulb excitability in the postnatal rat. Brain Res. 470: 69-75.

Wilson, D.A. and Sullivan, R.M. 1991. Olfactory associative conditioning in infant rats with brain stimulation as reward. II. Norepinephrine mediates a specific component of the bulb response to reward Behav. Neurosci. 105: 843-849.

Winder, D.G., Mansuy, I.M., Osman, M., Moallem, T.M., and Kandel, E.R. 1998. Genetic and pharmacological evidence for a novel, intermediate phase of long-term potentiation suppressed by calcineurin. Cell 92: $25-37$.

Woo, C.C., Wilson, D.A., Sullivan, R.M., and Leon, M. 1996. Early locus coeruleus lesions increase the density of $\beta$-adrenergic receptors in the main olfactory bulb of rats. Int. J. Dev. Neurosci. 14: 913-919.

Xing, J., Kornhauser, J.M., Xia, Z., Thiele, E.A., and Greenberg, M.E. 1998 Nerve growth factor activates extracellular signal-regulated kinase and p38 mitogen-activated protein kinase pathways to stimulate CREB serine 133 phosphorylation. Mol. Cell Biol. 18: 1946-1955.

Yang, S.N., Tang, Y.G., and Zucker, R.S. 1999. Selective induction of LTP and LTD by postsynaptic [Ca2 +]i elevation. J. Neurophysiol. 81: 781-787.

Yin, J.C. and Tully, T. 1996. CREB and the formation of long-term memory. Curr. Opin. Neurobiol. 6: 264-268.

Received July 19, 2000; accepted in revised form October 5, 2000

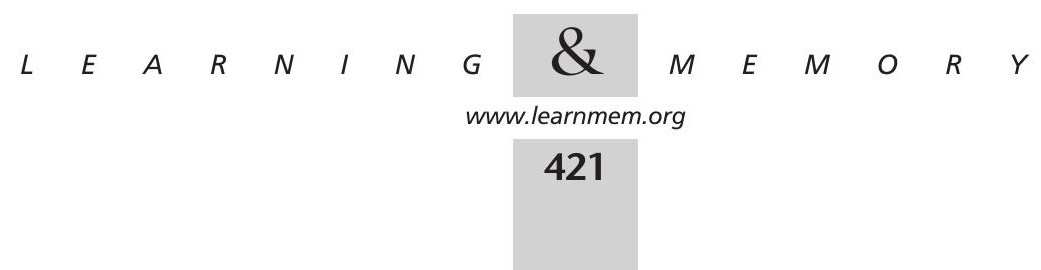




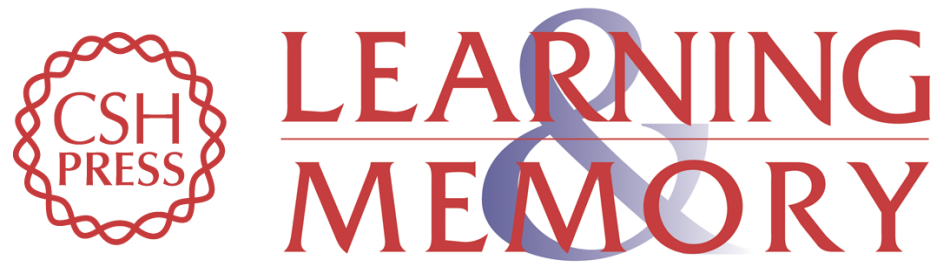

\section{Isoproterenol Increases CREB Phosphorylation and Olfactory Nerve-Evoked Potentials in Normal and 5-HT-Depleted Olfactory Bulbs in Rat Pups Only at Doses That Produce Odor Preference Learning}

Qi Yuan, Carolyn W. Harley, Jamie C. Bruce, et al.

Learn. Mem. 2000, 7:

Access the most recent version at doi:10.1101/lm.35900

References This article cites 46 articles, 9 of which can be accessed free at: http://learnmem.cshlp.org/content/7/6/413.full.html\#ref-list-1

License

Email Alerting Receive free email alerts when new articles cite this article - sign up in the box at the Service top right corner of the article or click here. 